\title{
Vitamin D Deficiency in Autism Spectrum Disorder: A Cross- Sectional Study
}

\author{
Maria G. Petruzzelli $D^{1},{ }^{1}$ Lucia Marzulli, ${ }^{2}$ Francesco Margari, ${ }^{1}$ Andrea De Giacomo, ${ }^{1}$ \\ Alessandra Gabellone, ${ }^{2}$ Orazio V. Giannico, ${ }^{2}$ and Lucia Margari ${ }^{2}$ \\ ${ }^{1}$ Department of Basic Medical Sciences, Neuroscience and Sense Organs, University of Bari "Aldo Moro", Bari, Italy \\ ${ }^{2}$ Department of Biomedical Sciences and Human Oncology, University of Bari "Aldo Moro", Bari, Italy \\ Correspondence should be addressed to Maria G. Petruzzelli; maria.petruzzelli@uniba.it
}

Received 19 December 2019; Revised 6 May 2020; Accepted 10 September 2020; Published 19 September 2020

Academic Editor: Giulia Bivona

Copyright (c) 2020 Maria G. Petruzzelli et al. This is an open access article distributed under the Creative Commons Attribution License, which permits unrestricted use, distribution, and reproduction in any medium, provided the original work is properly cited.

\begin{abstract}
Vitamin D plays a role in central nervous system (CNS) development. Recent literature focused on vitamin D status in children and adolescents with autism spectrum disorder (ASD), but with inconsistent results. Our case-control study is aimed at evaluating serum 25-hydroxyl-vitamin D $(25(\mathrm{OH}) \mathrm{D})$ concentration in children with ASD (ASD group, $n=54)$ compared to children affected by other neurological and psychiatric disorders (non-ASD group, $n=36$ ). All patients were admitted at the Complex Operative Unit of Child Neuropsychiatry, Polyclinic of Bari, Italy. 25(OH)D was quantified by chemiluminescence immunoassay and level defined as: deficiency $(<20 \mathrm{ng} / \mathrm{mL})$; insufficiency $(20-30)$; normality (30-100); toxicity ( $>100)$. Statistical analysis was performed using SPSS20 (significance $<0.05$ ). The ASD group showed $25(\mathrm{OH}) \mathrm{D}$ a mean level significantly lower than control $(p=0.014)$. Multivariable logistic regression analysis showed an association between ASD and vitamin D deficiency $(p=0.006)$. The nature of such association is unclear. Vitamin D deficiency may probably act as a risk factor for the development of ASD. Further studies are needed to unravel the role of vitamin D in ASD etiology and investigate its therapeutic potential.
\end{abstract}

\section{Introduction}

Vitamin D is a member of the family of steroid hormones mainly existing in two forms, ergocalciferol (vitamin D2), which is photochemically synthesized by plants, and cholecalciferol (vitamin D3), which is synthesized in the skin in the presence of ultraviolet rays B (UVB) resulting from sun exposure. In humans, a sequential 25-hydroxylation and $1 \alpha$-hydroxylation of vitamin D2 and vitamin D3 precursors take place in the liver and in the kidney, respectively, resulting in the synthesis of 25-hydroxycholecalciferol $(25(\mathrm{OH}) \mathrm{D})$ in the former and 1,25 dihydroxycholecalciferol $(1,25(\mathrm{OH}) 2 \mathrm{D})$ in the latter $[1,2]$. The active metabolite $1,25(\mathrm{OH}) 2-\mathrm{D}$, also called calcitriol, plays a direct action on bone tissue cells, activating osteoclastogenesis and bone resorption, and an indirect action, through the regulation of phosphocalcium homeostasis. In addition, the presence of vitamin $\mathrm{D}$ receptors (VDR) and enzymes involved in Vitamin D metabolism in tissues other than bone suggests that calcitriol carries out many other functions, including the regulation of innate and adaptive immunity and plays a neurotrophic and antioxidant role in the central nervous system (CNS) [3]. According to the Endocrine Society's Practice Guidelines, vitamin D deficiency is defined as $25(\mathrm{OH}) \mathrm{D}$ serum concentration $<20 \mathrm{ng} / \mathrm{mL}$, insufficiency as $21-29 \mathrm{ng} / \mathrm{mL}$ and sufficiency as at least $30 \mathrm{ng} / \mathrm{mL}$ for maximum musculoskeletal health [4]. It has been estimated that approximately $30 \%$ and $60 \%$ of children and adults worldwide are vitamin $\mathrm{D}$ deficient and insufficient, respectively [4]. In recent years, the extraskeletal impact of vitamin $\mathrm{D}$ deficiency has been an active area of research [2]. Epidemiological and case-control studies have often suggested a link between vitamin $\mathrm{D}$ deficiency and conditions such as type 1 and type 2 diabetes, connective tissue disorders, inflammatory bowel disorders, chronic hepatitis, food allergies, asthma and 
respiratory infections, and cancer [2]. The relationship between vitamin $\mathrm{D}$ deficiency and neurodevelopmental disorders is less clear, but, with the introduction of vitamin D into the broader family of neuroactive steroids [3], it is now conceivable that optimal levels of vitamin $\mathrm{D}$ are also necessary to preserve the neurological development and to protect the brain [1]. Autism spectrum disorder (ASD) is a part of a broad spectrum of neurodevelopmental disorders characterized by impairments of social interaction, verbal and nonverbal communication, and behaviour. ASD etiology is still unknown, but both genetic and environmental factors are hypothesized to play a causative role. Several observational studies have examined the association between vitamin D status and ASD in children and adolescents, achieving inconsistent results. Many case-control studies revealed that children with ASD have lower vitamin $\mathrm{D}$ concentrations than their healthy counterpart, suggesting that D-hypovitaminosis may be a risk factor for $\operatorname{ASD}(3, v b, v b)$, and vitamin $D$ supplementation useful for treating its symptoms. Here, we sought to produce further insight in this field by comparing serum levels of vitamin D between children with ASD and a control group of nonASD patients.

\section{Materials and Methods}

2.1. Participants. A retrospective chart review of records from inpatients referred to Child Neuropsychiatry Unit of University of Bari “Aldo Moro" from 2014 to 2018 was performed. According to the aim of the study, we selected all subjects responding to the following inclusion criteria: patients of both sex, under the age of 18 , whose $25(\mathrm{OH}) \mathrm{D}$ level was available. The missing data on $25(\mathrm{OH})$-vitamin $\mathrm{D}$ level or the evidence, from medical history, physical examination, and laboratory findings, of severe malnutrition or chronic diseases, potentially affecting normal vitamin D metabolism, were considered as exclusion criteria.

All the enrolled patients were subdivided into two groups, respectively, including children identified with ASD and children with other neuropsychiatric disorders different from ASD.

ASD diagnoses were defined by experienced child and adolescent psychiatrists according to the Diagnostic and Statistical Manual of mental disorders (DSM-5) criteria [5]. The diagnostic process, based on child observation and interaction, as well as on clinical interview with parents, was supported by administration of Autism Diagnostic Interview-Revised (ADI-R) [6] and Autism Diagnostic Observation Schedule, Second Edition (ADOS-2) [7] by properly trained psychologists.

The ADI-R is a standardized, semistructured interview during which parents or carers report information about an individual suspected of having an ASD. It assesses behavior across three domains: reciprocal social interaction, communication and language, restricted and repetitive, and stereotyped interests and behaviors. The ADOS- 2 is a semistructured assessment of communication, social interaction, play, and restricted and repetitive behaviors, widely accepted as a "gold standard" instrument for the diagnosis of ASD across age, developmental level, and language skills. One of four different modules may be administered according to the expressive language level and chronological age of the patient. All the evaluations were discussed in regular reliability meetings, supervised by the senior researcher.

2.2. Procedure. All patients underwent a comprehensive clinical assessment, including anamnestic interview, physical and neurological examination, and laboratory blood tests and instrumental evaluation by electrocardiogram, electroencephalogram, and brain magnetic resonance, when indicated. Serum concentrations of $25(\mathrm{OH})-\mathrm{D}$ (the hepatic metabolite of vitamin D) were determined by chemiluminescence immunoassay and expressed as $\mathrm{ng} / \mathrm{ml}$. Ranges indicative of a state of deficiency, insufficiency, normality, or toxicity were determined as previously reported [4]:

$$
\begin{gathered}
\text { Deficiency }=25(\mathrm{OH}) \mathrm{D}<20 \mathrm{ng} / \mathrm{ml} \\
\text { Insufficiency }=20 \mathrm{ng} / \mathrm{ml}<25(\mathrm{OH}) \mathrm{D}<30 \mathrm{ng} / \mathrm{ml} \\
\text { Normality }=30 \mathrm{ng} / \mathrm{ml}<25(\mathrm{OH}) \mathrm{D}<100 \mathrm{ng} / \mathrm{ml} \\
\text { Toxicity }=25(\mathrm{OH}) \mathrm{D}>100 \mathrm{ng} / \mathrm{ml}
\end{gathered}
$$

Written informed consents were achieved from parents, and the study was approved by the Ethical Committee of the Hospital Consortium Policlinic of Bari.

2.3. Statistical Analysis. Statistical analysis was performed using SPSS 20. Statistical significance $\alpha$ was fixed to 0.05 . Categorical variables were reported as absolute and relative frequencies. Continuous variables were reported as median and IQR and compared between ASD and non-ASD patients through the Wilcoxon rank sum test in order to account for nonnormality, evaluated through the Shapiro-Wilk test, and heteroscedasticity, evaluated through the Bartlett test. The minimum sample size calculated through Altman's monogram was 30 for each group with a statistical power of $80 \%$ and a standardized difference of 1 .

A multivariable binary logistic regression model for vitamin $D$, age, and sex was then fitted in order to assess the effect of vitamin D levels on the presence of ASD through the estimation of adjusted odds ratios. The sample size was idoneous relying on the one in ten rule. The goodness of fit of the model was evaluated through the Hosmer Lemeshow test and the pseudo $R^{2}$ of Nagelkerke.

\section{Results}

The ASD group included 54 patients, while 36 subjects bearing other neuropsychiatric disorders were included in the control group. Demographic and clinical features of the two study groups are summarized in Table 1. The non-ASD group included 15 patients with diagnosis of neurodevelopmental disorders other than ASD (4 with intellectual disability, 3 with attention-deficit/hyperactivity disorder, 3 with motor disorders, 2 with specific learning disorder, and 3 with language disorder), 11 patients with diagnosis of psychiatric disorder (5 with depressive disorders, 3 with an anxiety disorders, 2 with obsessive-compulsive disorder, and 1 with psychotic disorder), and 10 patients with 
TABLE 1: Demographic and clinical feature of the study samples.

\begin{tabular}{lcc}
\hline & ASD $(n=54)$ & Non-ASD $(n=36)$ \\
\hline Age (years) mean ( \pm S.D.) & $6.87( \pm 3.92)$ & $11.28( \pm 4.44)$ \\
Gender & & \\
$\quad$ Male $n(\%)$ & $44(81.5)$ & $21(58.3)$ \\
$\quad$ Female $n(\%)$ & $10(18.5)$ & $15(41.7)$ \\
Ethnicity & Caucasian & Caucasian \\
Residence & South of Italy & South of Italy \\
\hline
\end{tabular}

TABle 2: Mann-Whitney U test for vitamin D levels distribution between ASD and non-ASD patients.

\begin{tabular}{lc}
\hline & Vit. D \\
\hline Mann-Whitney $U$ & 673.500 \\
Wilcoxon $W$ & 2158.500 \\
$Z$ & -2.460 \\
Asymp. Sig. (2-tailed) & 0.014 \\
\hline
\end{tabular}

neurological diseases (5 with epilepsy, 3 with migraine, and 2 with a peripheral neuropathy).

A multivariable logistic regression analysis showed that ASD was significantly associated $(p=0.006)$ with lower levels of vitamin D (Table 3). Moreover, the odds of 25(OH)D deficiency in ASD subjects appeared 10.31 times higher than those in the control group.

As reported in Table 2, the mean level of serum 25(OH)D was significantly lower in the ASD group as compared to non-ASD group $(18.61 \pm 8.33 \mathrm{ng} / \mathrm{mL}$ versus $24.62 \pm 13.18$ $\mathrm{ng} / \mathrm{mL} ; p=0.014)$.

\section{Discussion}

The main finding of this study consisted in a significant association between ASD and the occurrence of Vitamin D deficiency $(25(\mathrm{OH}) \mathrm{D}<20 \mathrm{ng} / \mathrm{ml})$. Such result appears of interest if one takes into account that a remarkable prevalence of vitamin D deficiency is emerging in the general population worldwide [4]. Recent epidemiological data in Italy reported a prevalence of vitamin D deficiency in line with European data, ranging $4-7 \%, 1-8 \%$, and $12-40 \%$ according to the age intervals of 1-6 years, 7-14 years, and 15-18 years, respectively [8]. Consistent with the high prevalence of hypovitaminosis $\mathrm{D}$ into Italian pediatric population $[8,9]$, we found $25(\mathrm{OH}) \mathrm{D}$ mean levels $<30 \mathrm{ng} / \mathrm{dL}$ in both our clinical groups but, interestingly, ASD patients showed concentrations significantly lower than subjects with different neurological or psychiatric disorders. In a recent review [10], Wang et al. summarized results from 11 case-control studies comparing serum concentration of vitamin D between ASD children and healthy controls [11-21], supporting the hypothesis of an intriguing association between these two conditions [12, 14-18, 20, 21].

In the general population, D-hypovitaminosis is associated by limited sunlight exposure, low UVR level, low dietary vitamin $\mathrm{D}$ intake, non-Caucasian ethnicity, malabsorption syndromes, obesity, hepatic/renal failure, and some medica-
TABle 3: Age- and sex-adjusted association between levels of vitamin $\mathrm{D}$ and ASD.

\begin{tabular}{lccccc}
\hline Vitamin D & $\begin{array}{c}\text { ASD } n \\
(\%)\end{array}$ & $\begin{array}{c}\text { Non-ASD } n \\
(\%)\end{array}$ & OR & $\begin{array}{c}95 \% \text { CI for } \\
\text { OR }\end{array}$ & $\begin{array}{c}p \\
\text { value }\end{array}$ \\
\hline Normality & $6(11.1)$ & $9(25)$ & 1.00 & - & - \\
Insufficiency & $13(24.1)$ & $15(41.7)$ & 3.29 & $0.61-17.71$ & 0.166 \\
Deficiency & $35(64.8)$ & $12(33.3)$ & 10.31 & $1.96-54.22$ & $\mathbf{0 . 0 0 6}$ \\
\hline
\end{tabular}

tions $[4,8]$. All subjects included in this study are resident in the South of Italy, suggesting they are exposed to similar weather conditions. However, we are unable to exclude that specific lifestyle factors, as indoor environment, extensive clothing cover, or excessive sun avoidance may have led to different sunlight exposure between study patients. Similarly, repetitive and restricted dietary behaviors and food selectivity typically associated to ASD could negatively impact vitamin D dietary intake. A literature review [22] reported lower vitamin D dietary intakes in children with ASD compared to healthy controls [23-26], although this difference was not always statistically significant $[27,28]$.

Other authors hypothesize that D-hypovitaminosis is implicated in the ASD pathogenesis based on the severe vitamin D deficiency observed in this clinical setting, and our multivariable analysis is in line with such a picture. Modabbernia et al., in a sistematic evidence-based review, listed vitamin D deficiency as a nutritional risk factor for ASD [29]. It is currently thought that vitamin $\mathrm{D}$ deficiency cooperates with a wide range of additional environmental factors (obstetric complications, dysregulated steroidogenesis, maternal stress, maternal infection, etc.) in modulating multiple biological processes relevant to ASD, including calcium signaling abnormalities, mythocondrial dysfunctions, and neurotransmission [30]. Moreover, it is increasingly contemplated that neuroinflammation and immune dysfunctions play an etiologic role in different brain disorders, including autism, and, intriguingly, vitamin $\mathrm{D}$ is known to exert both anti-inflammatory and immunomodulatory effects in humans [31]. Over the last few years, a large body of research has been aimed at searching for links between ASD and aberrant immune function [32]. For instances, familial autoimmunity, maternal autoantibodies, and inflammation during gestation significantly increase the risk of ASD. Consistently, individuals with ASD show higher titers of autoantibodies and rates of immune dysfunctions or immune-mediated comorbidities than healthy population, and processes of neuroinflammation have been substantiated both ex vivo and in post mortem brain samples [33]. Two additional observations link vitamin $\mathrm{D}$ to immunity, the first standing in the capacity of immune cells to secrete vitamin $\mathrm{D}$ in both autocrine and paracrine fashion, the second based on the vitamin-D receptor (VDR) location in the brain as well as onto the surface of many immune cytotypes, as T- and B-cells, monocytes, macrophages, dendritic cells and neutrophilis [31]. Moreover, the VDR belongs to the neuro-steroid receptor family, thus further prompting future studies at investigating its role in ASD. Some reports showed the association of single nucleotide polymorphisms of the VDR gene with ASD, but their 
functional role is still far from being clarified. Finally, genetic aberrations of the VDR gene could affect vitamin D uptake and metabolism $[34,35]$, suggesting intriguing implications in the genetic susceptibility to ASD.

One of the major limitations of this study stands in its cross-sectional nature and small sample size. Furthermore, the absence of comparison with an additional healthy control sample and the assessment of influencing factors, as sun exposure and dietary patterns, should be considered as actual limitations and future direction of research.

\section{Conclusion}

Vitamin D deficiency due to genetic and/or environmental factors is common in ASD children and may represent a risk factor for developing ASD. Therefore, we believe that more frequent measurements of vitamin D levels in ASD patients may be considered a good clinical practice. Future prospective studies, supported by more translational experimental frameworks, should be aimed at clarifying the role of vitamin $\mathrm{D}$ in autism, even defining potential clinical benefits from its supplementation.

\section{Data Availability}

The data used to support the findings of this study are included within the supplemental information file.

\section{Conflicts of Interest}

The authors declare that there is no conflict of interest regarding the publication of this paper.

\section{Supplementary Materials}

Demographic features and vitamin D level for each ASD and non-ASD patient. (Supplementary Materials)

\section{References}

[1] C. Di Somma, E. Scarano, L. Barrea et al., "Vitamin D and neurological diseases: an endocrine view," International Journal of Molecular Sciences, vol. 18, no. 11, pp. 1-26, 2017.

[2] R. Marino and M. Misra, "Extra-skeletal effects of vitamin D," Nutrients, vol. 11, no. 7, pp. 1-23, 2019.

[3] D. W. Eyles, T. H. J. Burne, and J. J. McGrath, "Vitamin D, effects on brain development, adult brain function and the links between low levels of vitamin D and neuropsychiatric disease," Frontiers in Neuroendocrinology, vol. 34, no. 1, pp. 47-64, 2013.

[4] M. F. Holick, "The vitamin D deficiency pandemic: approaches for diagnosis, treatment and prevention," Reviews in Endocrine \& Metabolic Disorders, vol. 18, no. 2, pp. 153165, 2017.

[5] APA, Diagnostic and statistical manual of mental disorders $\left(D S M-5^{\circledR}\right)$, American Psychiatric Pub, 2013.

[6] C. Lord, M. Rutter, and A. Le Couteur, "Autism diagnostic interview-revised: a revised version of a diagnostic interview for caregivers of individuals with possible pervasive developmental disorders," Journal of Autism and Developmental Disorders, vol. 24, no. 5, pp. 659-685, 1994.
[7] C. Lord, M. Rutter, P. DiLavore, S. Risi, K. Gotham, and S. L. Bishop, Autism Diagnostic Observation Schedule, Second Edition (ADOS-2) Manual (Part I): Modules 1-4, Western Psychological Services, Torrence, CA, 2012.

[8] G. Saggese, F. Vierucci, F. Prodam et al., "Vitamin D in pediatric age: consensus of the Italian Pediatric Society and the Italian Society of Preventive and Social Pediatrics, jointly with the Italian Federation of Pediatricians," Italian Journal of Pediatrics, vol. 44, no. 1, pp. 1-40, 2018.

[9] SIPPS, Vitamina D in età pediatrica, Sintesi InfoMedica S.r.l., 2015.

[10] T. Wang, L. Shan, L. Du et al., "Serum concentration of 25hydroxyvitamin D in autism spectrum disorder: a systematic review and meta-analysis," European Child \& Adolescent Psychiatry, vol. 25, no. 4, pp. 341-350, 2016.

[11] J. B. Adams, T. Audhya, S. McDonough-Means et al., "Nutritional and metabolic status of children with autism vs. neurotypical children, and the association with autism severity," Nutrition and Metabolism, vol. 8, 2011.

[12] A. Bener, A. Khattab, and M. Al-Dabbagh, "Is high prevalence of vitamin D deficiency evidence for autism disorder?: In a highly endogamous population," Journal of Pediatric Neurosciences, vol. 9, no. 3, pp. 227-233, 2014.

[13] Ç. Ułur and C. K. Gürkan, "Serum vitamin D and folate levels in children with autism spectrum disorders," Research in Autism Spectrum Disorder, vol. 8, no. 12, pp. 1641-1647, 2014.

[14] L. Du, L. Shan, B. Wang, J. Y. Feng, Z. XuDa, and F. Y. Jia, "Serum levels of 25-hydroxyvitamin D in children with autism spectrum disorders," Chinese Journal Of Contemporary Pediatrics, vol. 17, no. 1, pp. 68-71, 2015.

[15] E. Fernell, S. Bejerot, J. Westerlund et al., "Autism spectrum disorder and low vitamin D at birth: a sibling control study," Molecular Autism, vol. 6, no. 1, 2015.

[16] Z. L. Gong, C. M. Luo, L. Wang et al., "Serum 25hydroxyvitamin D levels in Chinese children with autism spectrum disorders," Neuroreport, vol. 25, no. 1, pp. 23-27, 2014.

[17] N. A. Meguid, A. F. Hashish, M. Anwar, and G. Sidhom, "Reduced serum levels of 25-hydroxy and 1,25-dihydroxy vitamin D in Egyptian children with autism," Journal of Alternative and Complementary Medicine, vol. 16, no. 6, pp. 641$645,2010$.

[18] G. A. Mostafa and L. Y. AL-Ayadhi, "Reduced serum concentrations of 25-hydroxy vitamin $\mathrm{D}$ in children with autism: relation to autoimmunity," Journal of Neuroinflammation, vol. 17, p. 9, 2012.

[19] A. M. Neumeyer, A. Gates, C. Ferrone, H. Lee, and M. Misra, "Bone density in peripubertal boys with autism spectrum disorders," Journal of Autism and Developmental Disorders, vol. 43, no. 7, pp. 1623-1629, 2013.

[20] K. Saad, A. A. Abdel-Rahman, Y. M. Elserogy et al., "Vitamin $\mathrm{D}$ status in autism spectrum disorders and the efficacy of vitamin D supplementation in autistic children," Nutritional Neuroscience, vol. 19, no. 8, pp. 346-351, 2015.

[21] T. M. H. F. de Souza, H. C. Polonini, W. F. Gattaz, N. R. B. Raposo, and E. B. Baptista, "Low serum levels of 25hydroxyvitamin D (25-OHD) in children with autism," Trends in Psychiatry and Psychotherapy, vol. 34, no. 3, pp. 161-163, 2012.

[22] H. Mazahery, C. A. Camargo, C. Conlon, K. L. Beck, M. C. Kruger, and P. R. von Hurst, "Vitamin D and autism spectrum disorder: a literature review," Nutrients, vol. 8, no. 4, pp. 1-35, 2016. 
[23] L. G. Bandini, S. E. Anderson, C. Curtin et al., "Food selectivity in children with autism spectrum disorders and typically developing children," The Journal of Pediatrics, vol. 157, no. 2, pp. 259-264, 2010.

[24] A. Emond, P. Emmett, C. Steer, and J. Golding, "Feeding symptoms, dietary patterns, and growth in young children with autism spectrum disorders," Pediatrics, vol. 126, no. 2, 2010.

[25] J. Graf-Myles, C. Farmer, A. Thurm et al., "Dietary adequacy of children with autism compared with controls and the impact of restricted diet," Journal of Developmental and Behavioral Pediatrics, vol. 34, no. 7, pp. 449-459, 2013.

[26] M. H. Zimmer, L. C. Hart, P. Manning-Courtney, D. S. Murray, N. M. Bing, and S. Summer, "Food variety as a predictor of nutritional status among children with autism," Journal of Autism and Developmental Disorders, vol. 42, no. 4, pp. 549556, 2012.

[27] A. C. Herndon, C. DiGuiseppi, S. L. Johnson, J. Leiferman, and A. Reynolds, "Does nutritional intake differ between children with autism spectrum disorders and children with typical development?," Journal of Autism and Developmental Disorders, vol. 39, no. 2, pp. 212-222, 2009.

[28] S. Marí-Bauset, A. Llopis-González, I. Zazpe-García, A. MaríSanchis, and M. Morales-Suárez-Varela, "Nutritional status of children with autism spectrum disorders (ASDs): a case-control study," Journal of Autism and Developmental Disorders, vol. 45, no. 1, pp. 203-212, 2014.

[29] A. Modabbernia, E. Velthorst, and A. Reichenberg, "Environmental risk factors for autism: an evidence-based review of systematic reviews and meta-analyses," Molecular Autism, vol. 8, no. 1, pp. 1-16, 2017.

[30] A. Ali, X. Cui, and D. Eyles, "Developmental vitamin D deficiency and autism: putative pathogenic mechanisms," The Journal of Steroid Biochemistry and Molecular Biology, vol. 175, pp. 108-118, 2018.

[31] E. Kočovská, F. Gaughran, A. Krivoy, and U. C. Meier, "Vitamin-D deficiency as a potential environmental risk factor in multiple sclerosis, schizophrenia, and autism," Frontiers in Psychiatry, vol. 8, pp. 1-11, 2017.

[32] G. Murdaca, A. Tonacci, S. Negrini et al., "Emerging role of vitamin $\mathrm{D}$ in autoimmune diseases: an update on evidence and therapeutic implications," Autoimmunity Reviews, vol. 18, no. 9, p. 102350, 2019.

[33] H. K. Hughes, E. Mills Ko, D. Rose, and P. Ashwood, "Immune dysfunction and autoimmunity as pathological mechanisms in autism spectrum disorders," Frontiers in Cellular Neuroscience, vol. 12, pp. 1-26, 2018.

[34] S. Biswas, B. Kanwal, C. Jeet, and R. S. Seminara, "Fok-I, Bsm$\mathrm{I}$, and Taq-I variants of vitamin $\mathrm{D}$ receptor polymorphism in the development of autism spectrum disorder: a literature review," Cureus, vol. 10, no. 8, 2018.

[35] A. Cieślińska, E. Kostyra, B. Chwała et al., "Vitamin D receptor gene polymorphisms associated with childhood autism," Brain Sciences, vol. 7, no. 9, 2017. 